\title{
'T OPSCHRIFT VAN BATOE BERAGONG OP SUMATRA.
}

Het was indertijd een zeer verdienstelijk werk van den heer R. Friederich, dat hij de opschriften van Batoe Beragong en Pagger Roejong ontcijferde, uitgaf en met eene proeve van vertaling voorzag 1. De taal waarin beide opschriften opgesteld zijn, werd door hem Sanskrit genoemd, en inderdaad zal niemand betwisten dat de vervaardiger der inscriptie van Batoe Beragong zich verbeeld heeft een stuk in . Sanskrit te leveren. Eigenlijk is het eene soort van brabbeltaal. Van 't andere opschrift is het op 't eerste gezicht niet zoo gemakkelijk te beslissen of de maker zijn geheele werk voor Sanskrit hield, dan wel of hij met bewustheid een overmatig gebruik van min of meer verknoeide Sanskrit-woorden gemaakt heeft, terwijl de zinverbindende woordjes en grammatische vormen grootendeels inheemsch, laat ons zeggen: Oud Menangkabausch Maleisch, waren. Ook zonder overal den zin dier Oud-Menangkabausche woorden te verstaan, mogen we gerust beweren dat eene menigte daarvan in 't stuk voorkomen; o. a. madwayâdwaja in $\mathrm{r}$. $\mathbf{l}$ is geen Sanskrit, al is 't grondwoord een verknoeid Skr. woord; manguddharana in 8, maraksha-çila "welvoegelijkheid bewaren" in 16: manganumodana "behartigen" in 14; deze zijn alle klaarblijkelijk met de bekende voorvoegsels ma en mang gevormd. Telkens komt voor inan, duidelijk een voornaamwoord in den zin van "deze, dit", nog over in 't Menangkabausche di sinan "aldaar" 2. In de zinsnede butula ya manganumodana dharmmenan (d. i. dharmma + inan) mag butula een conjunctief wezen van Maleisch bëtul of niet, in geen geval heeft het iets met Sanskrit gemeen, evenmin als ya; ya m., enz. bet. "die

1 In Verbandelingen van het Batav. Genootschap, D. 26.

2 Dr. v. d. Tuuk heeft bereids in zijne Tob. Spr. bl. 288, met zijne gewone scherpzinnigheid, uit $d i$ sinan 't voormalig bestaan van inan opgemaakt. 
deze wet behartigt". Naast inan treffen we aan iná in 13; batw inẩ ça- (beter sa) sâsanenan (d. i. Skr. çấsana + inan) "deze steen met dit edict". Maleisch is bärang in 12; di parbwatkan in 9 ; sak nyang in 12 zal wel overeenkomen met een. Oudjavaansch sěk (of sök) nyang "de volheid van, veel"; punyâtấ is althans eene naar Polynesische accentregelen vervormde uitspraak van een Skr. woord, en 't daarop volgende yang ngürang 1 geheel en al inlandsch. In singâ tishthati, r. 3, vindt men eene verbinding van een zuiveren Skr.-vorm met singấ (of sing en dan álishthati); in 't eerste woord herkent men 't betr. vnmw. = Jav., en 't tweede zal wel de letterlijke vertaling zijn van een inheemsch woord $=$ Jav. madèg, zoodat sing ât. beteekent "welke regeert". Woorden als mpu ki (of kai?) laten we nog geheel ter zijde, en van andere als dhak of dhat, rentak, enz. stippen we slechts aan dat ze niets met Skr. gemeen hebben. Ook merken we in 't voorbịgaan op dat de drie eerste regels eene strophe in Cârdûlawikrîdita bevatten, beginnende met swasty astu (zoo is te lezen) prabhu (een vocatief) madwayâdwaja nrpa (vocatief!) ádityawarmma çriyâ (vermoedelijk een conjunctief). Dit is de eerste van de vier regels der strophe.

Elke poging om een stuk dat, in spijt van kwistig ingestrooide Skr.-woorden, geen Skr. is, uit die taal te gaan verklaren, moet onvermijdelijk mislukken. Nochtans komt er een klein gedeelte in 't edict voor, dat Skr. verbeelden moet en in zooverre op dien naam aanspraak heeft, en wel de Anushtubh aan 't slot warin de datum van 't stuk vervat is. Om dien datum is het ons hier te doen, want hij staat in onafscheidelijk verband met de dagteekening van 't stuk te Batoe Beragong. We zullen aantoonen dat beide inscripties 700 jaar jonger zijn dan de heer Friederich meende. Alleen de eerste, die in brabbelSanskrit, zullen we volledig behandelen, daar de lezing van 't opschrift te Pagger Roejong op te veel plaatsen onzeker is en de noodige kennis van 't Menangkabausch Maleisch ons ontbreekt.

Alvorens 't stuk van Batoe Beragong in zijn geheel te laten volgen, moeten we opmerken dat het niet weinig fouten vertoont, welke volstrekt niet den vervaardiger te wijten zijn, maar ten laste des steenhouwers komen. Hoe gebrekkig de kennis des

1 Hier en elders las de heer Friederich anders, uitgaande van de veronderstelling dat het stuk Skr. moest wezen; we verwijzen voor onze lezingen naar 't facsimile. 
opstellers ook was, kende hij toch de hoofdregelen der verskunst, betgeen niemand bevreemden zal die weet dat ook de Kawi-gedichten in Indische versmaten zijn, en er is geen reden denkbaar waarom men op Sumatra de Indische verskunst minder nagevolgd zou hebben dan op Java. Er komen in 't stuk fouten voor, die onmogelijk 't werk zijn van den anders jammerlijken dichter. Bị andere fouten, tegen spraakkunst of spelling, is het moeielijker te beslissen, wie schuld heeft. Hoe het zij, het is hoofdzakelijk den steenhouwer te wijten dat enkele woorden volstrekt onverstaanbaar of verminkt zijn.

't Opschrift van Batoe Beragong bestaat uit drie strophen; de eerste en derde in Anushtubh, de tweede in Çârdûlawikrîdita. Jammer dat zulks de aandacht van den Heer Friederich ontsnapt is, behalve in ' $\mathrm{t}$ geval der 3 de strophe. De versmaat toch is 't allerkrachtigste middel om twijfelachtige lezingen te herstellen of zekerheid te geven omtrent de ware lezing. Billijkerwijze zijn we verplicht te erkennen dat dichter en steenhouwer in dit opzicht geheel vrij zijn van blaam: zij hebben zorgvuldig, nauwkeurig en duidelijk de versafdeelingen aangegeven. Dat er van de lezing en woordverdeeling van den Heer Friederich nagenoeg niets overblijft, is een natuurlijk gevolg van de omstandigheid dat hein de versmaat onbekend is gebleven. Voor de juistheid onzer eigene ontcijfering verwijzen we den lezer naar 't facsimile, voorkomende in Verh. Batav. Gen., D. 26, achter bl. 99.

$\mathrm{Na}$ 't gebruikelijke $\mathrm{O} m$ ! heeft de inscriptie de volgende Anushtubh, waarvan de pâdla's behoorlijk door leesteekens afgedeeld zijn :

dwâre rasha bhûje rûpe | gat-au warshâç ca kârtike | suklah pañcatithis some | bajrendradi subham tu sat ||

Hierin zijn een paar afschrijversfouten: de au in gatau, uitgedrukt door 't teeken der lange $a$ achter, en dat der $a i$ vóór den medeklinker, komt hier volstrekt niet te pas. Nu weten we uit het oud-javaansch, dat $a i$ en $e$ van lieverlede verward werden, en zelfs in de Balineesche afschriften $a i$ als $e$ wordt uitgesproken; in onze inscriptie zelve zullen we zoo. straks $a i$ in stede van $e$ geschreven vinden. Waar ai met $e$ samenvalt, heeft ook au de waarde van $o$ gekregen; dus galau vertegenwoordigt ook gato. Ook dit is evenwel de ware vorm niet op onze plaats, want bij 't meervoud varshäç behoorde ook 't mv. gata te staan. Wat de lettervormen betreft, die door den eersten ontcijferaar verkeerd gelezen zijn, vergelijke men in regel 19 
van 't opschyift te Pagger Roejong den eersten pâda der strophe: subham (of: sugam) astu gate çâke; over dit laatste straks meer. De tweede afschrijversfout is bajrendradi; lees: bajrendrádi:

De fouten des dichters ten opzichte van spraakkunst, spelling ex woordvoeging zijn meer in getal. Dat rasha gespeld wordt in stede van rast is eene kleinigheid, en des te verklaarbaarder dewijl rasha ook in 't Kawi de gewone schrijfwijze is. Suklah on subham moesten beide met $\ell$ worden uitgesproken en gespeld; doch hier zou de steenhouwer schuld kunnen hebben. De fouten tegen 't taalgebruik van 't Skr. zijn te menigvuldig om ze afzonderlijk op te sommen; in dragelijk Sanskrit zou men de geheele strophe - welker zin anders volkomen duidelijk is aldus kunnen uitdrukken: dwấrarasabhujarüpawarsheshu gateshu, kârttike, çukle (in proza: kârttikaçukle) pañcamatithau, somawâre, wajraindrẩlini ca çubhe sati. De ca "en, ook" achter warshấç is een stoplap. 't Letterteeken voor sluitende $t$ keert in 't stuk zelve niet terug, doch komt overeen met-wat daarvoor in Bengali-schrift gebruikelijk is. - De vertaling in barbaarsch Hollandsch, eenigermate een denkbeeld gevende van 't soort Sanskrit door den dichter gebezigd, is:

"In negen, zes, twee, een, jaren voorbijgegaan, in (de maand) Kârttika, lichte helft, de vijf dag, op Maandag, (de Yoga) Wajra, (de Karana van) Indra, enz., gunstig nu zijnde."

Voor hen die van Skr. geen hoofdvak gemaakt hebben, zijn de volgende aanteekeningen misschien niet onwelkom. Dwára, opening, duidt 9 aan, naar de 9 openingen des lichaams; rasa, smaak, zes, naar de 6 soorten van smaak; bhuja, arm, drukt twee uit; en rüpa, o. a. " enkel exemplaar, een stuks (vee, koopwaar)" één. De datum is derhalve 1269, natuurlijk Çâka, overeenkomende met 1347 na Chr. - Wajra, naar slechte uitspraak: bajra, is de naam van een yoga, en wel de $15^{\text {de }}$ in de rij volgens de 27 maanhuizen, doch de 9 de in de reeks volgens de 28 maanhuizen ${ }^{1}$. Welke rij hier gevolgd is, laat zich uit de gegevens in "t opschrift niet opmaken. Met endra, d. i. aindra, is bedoeld de "onder Indra staande" Karana Bawa 2. Dit laat zich wel vaststellen;' want de Karana Bawa komt o. a. overeen met de eerste helft der 5 de Tithi. Nu valt de datum van 't stuk juist op 'de 5de Tithi. Onder âdi zijn andere tijjdsbepalingen begrepen, dié in de opschriften niet zelden

1 Zie Colebrooke, Misc. Essays, II, 363.

Zie Brhat-Sanhitâ, 99, 4. 
mede opgegeven worden, als uren (muhuirla), e. dgl. We verwijzen naar Inscriptie II onder de Kawi-oorkonden.

De behandelde dagteekening is blijkbaar die van de bekendmaking van 't stuk. In 't eerste vers der volgende strophe treffen we weder een datum aan, en wel van één dag later. Daaruit leiden we af, dat die tweede datum den dag aanduidt waarop de heugelijke gebeurtenis door de inscriptie te vereeuwigen, moest plaats hebben. De tweede strophe, in Çârdûlawikrîdita, is door den werkman zoo deerlijk verknoeid dat enkele woorden volstrekt onverstaanbaar, gedeeltelịk zelfs onleesbaar geworden zijn, en dit gevoegd bij 't onvermogen' des dichters zijne gedachten in 't Sanskrit behoorlijk uit te drukken, maakt het voor ons zeer moeielijk die gedachten overal te raden.

- Er staat, behoudens een paar onleesbare letters die we met een vraagteeken willen aanduiden:

bhuhkarnne nawadarççane sa? 。 teje shte çaçî manggalai | sukl[i]e shashthi tiwir nrpottamagunairr ädityawtarmma nrpah | kshettrajniah c c ter âçeshadharanînâm bhâsurâwâçawân | haçâno nrpa âsanottamasad âçâdyam prawaçtas sabhâ ||

Deze strophe wemelt van vergissingen van den kant van schrijver en afschrijver. Bhıhkarnne is een zinledige klank; de dichter moet geschreven hebben bhâhkî́rnne; vermoedelijk schreef de werkman volgens dictaat, en verondersteld dat lange $\hat{a}$ reeds toen, gelijk thans nog in 't Menangkabausch en in 't Javaansch als $\stackrel{\circ}{a}$ werd uitgesproken, en in aanmerking genomen dat de $u$ door Wisarga gevolgd nauwelijks van de $o$ te onderscheiden was, gelijk tegenwoordig ten minste in 't Javaansch 't geval is, dan laat zich de spelling bhuh voor bhâh heel wel verklaren; het teeken voor de $\hat{\imath}$ is eenvoudig vergeten of door den tijd uitgewischt. - Tusschen sa en teje staat eene onleesbare letterverbinding: in elk geval verkeerd, want er worden twee korte lettergrepen vereischt; gissenderwijze vullen we in bitr (voor witr). Teja, als stam, in plaats van tejah, is slecht Skr., doch heeft niets bevreemdends daar het ook in Kawi de gewone vorm is. Ashta, waarvan de locatief door ashte wordt voorgesteld, in den zin van as/tama "achtste" bestaat in "t Skr. evenmin als panca in den zin van pancama, hoewel de Sumatraansche hofpoëet uit de volheid zijner macht in de eerste strophe aan panca. 't karakter van een rangtelwoord heeft toegekend. Çaçî, een nominatief, is eene taalfout voor den locatief çaçini. Maniggalai is eene wanspelling voor manggale; 
over de verwarring van ai en $e$ is hierboven reeds gesproken. In suklie staat eene $i$ te veel. Shashthi is eene taalfout voor shashthî; de maat wijst uit dat hier de dichter schuld heeft. Tiwir is eene schrijffout voor tithir, of 't dwarsstreepje in de letter is uitgesleten. In gunairr is $\epsilon \mathrm{r}$ eene $r$ te veel. Adlityawtarmma is eene vergissing voor âdittyavarmmâ, en dit laatste wanspelling voor Adlityawarmmâ. Kshettra is wanspelling voor kshetra. Wat er vóór ter staat, is onleesbaar; er worden twee korte lettergrepen vereischt, wellicht sami, dat de werkman hoorde uitspreken sěmi, waarop hij $s m i$ griffelde; intusschen lijken de karakters meer op pti dan op smi. In âcesha is de lange $\vec{a}$ 't werk des afschrijuers. Haçâno is een monster; de

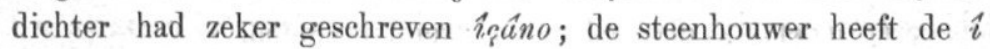
vergeten, tenzij die uitgesleten is, en schreef eene stomme $h$ als draagster van den klinker. âçâdlyam, zóó als het er staat, is in 't geheel niets; ik gis dat âsârlyâm bedoeld is, slaande op sabhâ, schrijf- of taalfout voor sabhäm (sabhäm). Pravaçtas is niets; de afschrijver heeft wederom eenen klinker vergeten, en eene slechte uitspraak gehoord of zelf slecht gehoord; er is gemeend prawishtas. De caesuur in de verzen is niet overal volgens de regelen der Indische verskunst aangebracht, doch juist hetzelfde geldt ook van de Cârdûla-verzen in de Oudjavaansche gedichten. Wij laten de strophe nu nogmaals volgen, gezuiverd van zulke fouten als den afschrijver te wijten zijn: bhâhkîrnne nawadarççane sa(bitr) teje 'shte çaçî manggale çukle shashthi tithir nrpottamag:unair âdityawarmmâ $\mathrm{n} r \mathrm{pa} h$ kshetrajnah (sami) ter açeshadharanînâm bhâsurâwâsawân icâno nrpa âsanottamasad âsâdyâm (?) prawishtas sabhâm.

Dit laat zich ten naastenbij vertolken met:

"Als met stralen bezet pas zichtbaar is de (zonne) glans, in de achtste maand (d. i. Kârttika), op Dinsdag, in de lichte helft, de zesde dag, heeft koning Adityawarman, met uitstekende koninklijke deugden (nl. begaafd), goed thuis in de (zeden en gebruiken) aller landen, bezitter eener prachtige woning, als heerschend vorst op den verhevenen zetel tronende, in het te betrekken (?) hof zijne intrede gedaan."

Uit vergelijking van de twee behandelde strophen blijkt, dunkt me, zooveel, dat de inscriptie onthuld is, om zoo te zeggen, des Maandags, en dient, zoowel om de heugelijke gebeurtenis van den volgenden dag te verkondigen, als om die te vereeuwigen. Die gebeurtenis was de intrede van Adityawar- 
man in zijn paleis. Of daarin opgesloten ligt dat hịj toen eerst de regeering aanvaardde, volgt niet met gewisheid, doch is hoogst waarschịnlijk, omdat îçâno nrpah anders geheel overtollig ware, en zelfs de grootste pruldichter denkt toch iets bij hetgeen hij schrijft.

Bij zulk een plechtig feest mogen offers niet ontbreken, en aan de vermelding en verheerlijking hiervan is de derde strophe gewijd, luidende:

pushpakotisahaçrâni | teshâm gandham prathat-trthat | âdittyawarmmabhûpâla - | homagandho samo bhawet ||

In 't eerste samengestelde woord lijkt eerder toti dan kot $i$ te staan; gelukkig doet het niets ter zake, want dat de dichter koti geschreven heeft, is niet twijfelachtig; sahaçrâni bevat twee spel- en uitspraakfouten, moest wezen sahasrâni. - 't Onzijdige gandham is Sauskrit op dezelfde wijze als "het geur" Nederlandsch. - Voor trthat, dat niets is, leze men prathat. Om een denkbeeld te geven van taal en stijl, willen we de verzen in overeenkomstig barbaarsch Nederlandsch overbrengen.

"Duizenden millioenen ${ }^{1}$ van bloemen haar geur dat zich overal verspreidt, zal de geur van Koning Adityawarman's offerande evenaren." De bedoeling is licht genoeg te vatten.

't Opschrift van Pagger Roejong, ook afkomstig van Koning Adityawarman, door den Heer Friederich op onverklaarbare wijze in Adityadharma omgedoopt, is van iets latere dagteekening. De strophe, waarin de datum vervat is (r. 19, vg.) luidt: sugam astu gate çâke | wasur mmuni bhujâ sthala $(m)$ | waiçâkapancadaçake | site baddhaç (P) ca, ran̆jyatu ||

Of er sugam bedoeld is of subham (1. çubham) is niet te onderscheiden; beide komen op hetzelfde neêr. - De $j$ in bhuja staat er eigenlijk niet; nog veel minder bhîla, gelijk de eerste ontcijferaar wilde, want dat is volstrekt onmogelijk wegens de versmaat. - Ook staat er niet pancadaçake, maar pancadatake, al is buiten kijf 't eerste bedoeld. Voor baddhaç ca schijnt ejgenlijk baddhak of baddhat ca gegriffeld te wezen. De heer Friederich verandert voorts de $a$ in $u$, en vat Buddhaç ca ranjyatu op als: Buddha zal (of moge) genegen gemaakt worden. Hetzij men de gissing van F. aannemeiijk achte en met hem in ranjyatu eene taalfout zie voor ranjyatâm, of wel oordeele dat bedoeld is rajyatu, in beide gevallen blijft er eene taalfout

1 Koti is eig. tien millioen. 
niet weg te cijferen. Om niet meer veranderingen te maken dan strikt noodzakelijk is, zullen we 't baddha van den tekst maar onveranderd laten, want onvertaalbaar is baddhaç ca rajyatu (ongrammatisch: ranjyatu) niet. De vertaling is als volgt:

"Er rij geluk! in 't jaar van Çaka verloopen: acht, zeven, twee, één; op den vijftienden dag van (de maand) Waiçâkha, in de lichte helft; ook de gevangene moge genoegen hebben!"

Wasu is de benaming van zekere lichtgeesten, en als zoodanig een term voor 't getal 8 ; muni duidt zeven aan, naar de 7 muni's of $r$ shi's, de sterren van den Grooten Beer; bhuja , een bijvorm van bhuja, arm, drukt twee uit; sthala, vaste grond, 't land, drukt gelijk elk woord voor aarde, 't getal één uit. 't Enkelvoud "de gevangene" in stede van "de gevangenen" zal wel een offer wezen aan de onverbiddelijke eischen der versmaat. Bij heugelijke gebeurtenissen, als inhuldiging, enz. is de koning verplicht de gevangenen op vrije voeten te stellen '

De dagteekening van 't opschrift te Pagger Roejong is derhalve 15 Waiçakkha 1278 Câka, overeenkomende met 1356 na Chr., en 9 jaar jonger dan 't vorige stuk van denzelfden koning Adityawarman.

We besluiten ons opstel met eenige opmerkingen aangaande den vorm der op beide inscripties gebruikte letterteekens.

De karakters onderscheiden zich weinig van die welke men in gelijktijdige of iets oudere Oudjavaansche opschriften aantreft. Het verdient echter bijzondere opmerking, dat de twee schriftvormen van 't Javaansch die men thans loopend en liggend schrift mag noemen, in de Sumatraansche stukken door elkander gebruikt worden, met dit onderscheid dat de letters nog niet schuinsch staan. Met andere woorden, de ophaal welke in de eerste schriftsoort, overeenkomende met Jav. staand schrift, achter den neêrhaal, en evenwijdig daarmêe, getrokken is, wordt in de tweede soort door den neêrhaal heen weêr naar boven getrokken of valt daarmeê samen, terwijl dan meestal de laatste haal een hoorntje heeft. Ten einde de overeenkomst dier twee lettersoorten met de Javaansche 't gemakkelijkst te bespeuren, heeft men den laatsten haal der Javaansche letters, welke eigenlijk het teeken der lange $a$ is, wegtedenken. Wat de Javanen bijv. de aksåra k̊a noemen, is 't letterteeken, niet van $k a$,

1 De woorden die onmiddellijk de strophe volgen zijn te lezen krtir iyam niet krtar ayam; de i's zijn door den werkman vergeten, of nitgesleten. 
'T OPSCHRIFT VAN BATOE BERAGONG OP SUMATRA. 297

maar van $k \hat{a}$, thans in de heerschende uitspraak klinkende als $k a ̊$. Dit belet niet dat de Javanen de eigenlijke waarde van hun karakters vergeten zijn, en $k \hat{d}$ inderdaad als een niet-samengesteld teeken beschouwen, en als zoodanig toepassen.-Hetzelfde geldt van de Balineezen, en dewijl de Balineesche Hss. der Oudjavaansche letterkundige gewrochten dezelfde eigenaardigheid vertoonen, moet de vervorming der oude schrijfwijze en de vaststelling der hedendaagsche eenige eeuwen oud zijn, al valt die ook na den val van 't rijk van Madjapahit.

Van de twee schriftsoorten, de loopende en de staande, is de eerste 't dichtst bij den oorspronkelijken vorm gebleven, daargelaten 't hellende er van.
Leiden, 14. Maart 72.
H. Kern. 